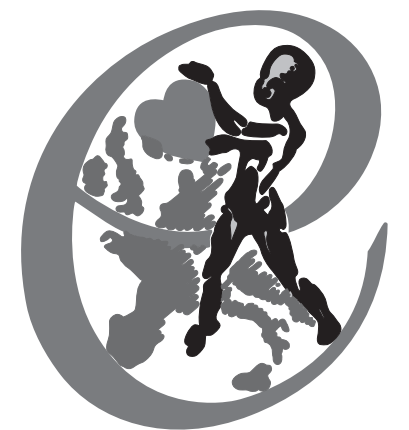

\section{The 44th Annual Meeting in Innsbruck}

The 44th Annual Meeting of the Association took place in Innsbruck from May 26 to 29. It started with an Update Course on Paediatric Electrophysiology. The update on course gave an excellent opportunity to update knowledge on specific problems seen in young patients with arrhythmias. The main topics were management of clinical arrhythmias, atrioventricular block and pacing in children, and arrhythmias in patients with congenital heart disease. Active participation and lively discussions proved that this update on course was really needed. The Council of the Association appreciates the efforts of the Cardiac Dysrhythmias and Electrophysiology Working Group for organising this excellent course.

The Annual Meeting itself was also a real success. This was the very first time that the Annual Meeting was organised together with the Japanese Society for Cardiology and Cardiac surgery. We also witnessed co-operation in the Scientific programme. There were several joint sessions that raised active high-quality discussions in a friendly atmosphere. The Council of the Association is truly grateful to Professor Joerg-Ingolf Stein and his team for the excellent work they undertook in organising our 44th Annual Meeting.

The audience of 500 paying attendees enjoyed high-quality scientific sessions, complemented by "state of the art" lectures. The first session dealt with "Intercultural attitudes towards Quality of Life". It started with a lecture by Karma Ura titled "Gross National Happiness - Quality of life - That's what is all about". This lecture was transmitted live via Internet from Bhutan. The other lectures dealt with Left Heart Hypoplasia - new aspects on foetal diagnosis and management, Ablation of dysrhythmias, Diagnosis and Management of foetal dysrhythmia, Ethical approach to heart replacement therapy, Stress imaging in congenital heart diseases, Caring for the whole child, Marfan aortopathies, and Interprofessional needs for lifelong care.
A joint session of working groups for congenital surgery and interventional cardiology dealt with different options to close ventricular septal defect and with regulation of the amount of pulmonary blood flow. A task force for grown-ups with congenital heart disease organised a session discussing long-term management and outcome - registries of the congenital heart diseases. A working group for interventional cardiology organised a traditional session on successes and failures in the catheterisation laboratory. This session once again inspired active discussions in a positive and friendly manner. We maintained our tradition of providing a morphologic demonstration that was well attended.

This year, we received a total of 533 submissions for abstracts and posters, and accepted half of them, grading for presentation as abstracts, as moderated posters, and as posters. Posters were evaluated by 13 selected reviewers attending the Annual Meeting. Owing to the high quality of the abstracts and posters this year, we gave away four prizes, two for posters and two for moderated posters.

\section{Future Annual Meetings}

Please book the dates 18 through 21 of May, 2011, to attend the 45th AEPC Annual Meeting in Granada, Spain. The meeting is organised together with the Spanish Society of Cardiology, the European Association of Cardiothoracic Surgery, and the Japanese Society for Cardiology and Cardiac surgery. The venue is filled with history with Alhambra Castles in the neighbourhood. The scientific programme will be better than ever. The Annual Meeting will take place in Istanbul in 2012, in London in 2013, and in Helsinki in 2014. We now invite our members and national societies to submit applications to host the Annual Meeting for 2015 and 2016.

\section{New Council members}

In Innsbruck, André Bozio ended his period as President of the Association. He currently serves the 
Association for one more year as the past President. Dr Shak Qureshi started his 3-year period as President of the Association. We all wish Shak the best of luck in his demanding work.

As we intimated in our Newsletter for December, we found it necessary to replace one of the Council members and to elect a Secretary-GeneralElect during the Business Meeting in Innsbruck. All members were invited to make their own proposals for the replacement of the Councillor. We received no nominations either for the position of Councillor or for that of Secretary-General from the members. The Council proposed $\mathrm{Dr}$ Juan Comas, Chief Cardiac Surgeon from Madrid, Spain, as a new Council member for 2010-2013 and Dr Katarina Hanséus, Chief of Paediatric Cardiology and Paediatric Heart Surgery in Lund, Sweden, as the new Secretary-General-Elect. The Business Meeting accepted both of these proposals. Dr Eero Jokinen serves the Association as the SecretaryGeneral till the Annual Meeting in Granada in 2011. Thereafter, Dr Katarina Hanséus will take charge of the Office of Secretary-General. As a greater proportion of the paediatric cardiology workforce becomes female, the Council welcomes the opportunity for more female influence in its work. Dr Juan Comas replaces Dr Bohdan Maruszewski as a Council member. The Council thanks Bohdan for his active work in developing co-operation between cardiac surgeons and the Association.

\section{News from the Business Meeting}

The members discussed amending the constitution. Honorary member Ingrid Oberhänsli-Weiss proposed that there could not be more than one Officer from one country at a time. The other members attending the Business Meeting did not support her proposal, which aroused active discussion. The members stated that the activity of the Officers is a much more important issue than his/her nationality. The Secretary-General also proposed the possibility that the Council could appoint coopted members in the council. The business meeting decided that the council should review the Constitution and make a proposal of the possible amendments to be discussed during the next Business Meeting.

The Association also established a new working group: Working Group for Early Prevention of Heart Diseases. The working group will concentrate on early prevention of atherosclerosis and coronary heart disease. Those of you who are interested in working in the new working group may please contact the Secretary-General.

\section{New web page}

The database of the Association is working fine. It allows prompt updating of the membership database, online payment of annual subscription, online address - change, and other database-related services. The content of the web page, however, has often been outdated because of difficulties in updating due to a complicated programming language. Therefore, the Council has decided that the database should remain unchanged, but the Association will have a new web page. For this reason, we organised a ballot for the basic design of the new web page in June, 2010. A blue-blue background design won the ballot. The new web page should be functioning from the beginning of October, 2010. We will return with the new web page services later.

\section{The Association faces new challenges and is looking for a favourable future}

A total of 116 members have joined the Association during the previous year. We are especially pleased that 43 of them are new Junior members. We now have a total of 173 Junior members in the Association. New members will always bring with them new ideas and innovations. The overall membership of the Association now stands at 1057 paediatric cardiologists and other specialists working in the field of paediatric cardiology and its related disciplines. As far as we are aware, this makes the Association the largest in the whole world, and what is equally encouraging is that we now represent members from all continents.

Education is a major task of the Association. The Council, the National Delegates, and the Professional Advisory Committee discussed actively different means of harmonising training in Paediatric Cardiology in Europe. This includes assessment of training centres and site visits will be set into action in the future. Therefore, we have established a specific Educational Committee to accommodate these tasks.

The basic teaching courses comprise a strategic priority of the activities of the Association. Our current favourable economical situation makes it possible to support the working groups in organising new teaching courses and promoting exchanges of trainees. The Council looks forward to hearing further from the working groups whenever they find new ways of teaching and training. The Educational Committee will evaluate all suggestions, and then determine if the plans can be economically supported. The high-quality basic training courses have been made affordable for those 
in training, and they have therefore been well attended. We have received more applications for most of the courses and have been able to accommodate all of them. We now extend an invitation to all our members to ask and encourage their young colleagues in training to attend these exceptional courses. There is more information about the forthcoming courses on the web page of the association at http://www.aepc.org.

\section{Correct address?}

In order to receive Newsletters, and to ensure that "Cardiology in the Young" is delivered to the correct address, it is crucial that members keep the SecretaryGeneral informed of any change in address. Nevertheless, more and more information will be delivered via e-mail and appear on the web page of the Association. We ask all members, therefore, to ensure that their e-mail address is correct in the database of the Association. Information can easily be checked and corrected via "Address change" on the web page of the Association http://www.aepc.org.

A password and username is needed, however, to use this option. Anybody who does not remember the password and username should not hesitate to contact the Secretary-General who will provide you with the information needed.

In closing, I hope you have all enjoyed a relaxing period of vacation. Now, we are ready for the challenges we will face during the end of the year. I again invite all of you to join actively in the endeavours of the working groups of the Association, sharing your proposals, ideas, and wishes with all the members of the Council.

Eero Jokinen Secretary-General 